\title{
Design and Analysis of Flood Resisting Residential Building: A Case Study in Malappuram-KERALA
}

DOI:10.36909/jer.ACMM.16299

\author{
Atul Kumar Singh, Prerna Sharma, L. Krishnaraj, V.R. Prasath Kumar* \\ Department of Civil Engineering, Faculty of Engineering and Technology, \\ SRM Institute of Science and Technology, Kattankulathur - 603203, Tamil Nadu, India. \\ *Corresponding Author: prasathv@srmist.edu.in.
}

\begin{abstract}
Structural analysis and design are the backbone or the crucial aspects in civil engineering. The foremost important requirement in civil engineering is to design all of the members related to a building such as slabs, beams, columns and footings. The residential building is situated in Malappuram district of Kerala state. Flooding and its adverse effects on the structure has been a cause of concern affecting the safety of humans for a major cause of time. This paves way for the sustainability constraint and the concerns over climatic change and the worry of environmental causes are also taken as a major concern in people's minds. Flood resistant buildings must comply with all major health and safety constraints and must begin from the primary planning and must continue in each of the upcoming stages. Structural analysis and designing of the building is done according to the relevant IS codes and STAAD.Pro software. There are higher chances and risks embarking greater polls for the structure to fail due to waterlogging or the pressure imbibed due to the movement of course of water thus paving out the environmental constraint. Proper height must be allowed for the retaining walls, taking into account the future floods of greater magnitude and higher flow. Manufacturability constraint accounts to improper design of structural elements. Taking into account all these constraints proper designing must be done as per IS 456:2000 and modelling using REVIT Architecture.
\end{abstract}

Keywords: Structure Analysis, STAAD.Pro, Revit Architecture, Risk, Residential building 


\section{INTRODUCTION}

Malappuram is a district which is located in the southernmost tip of Kerala state and is the revenue district also hailed as the Malabar. It is also the most populous district in Kerala, consisting of almost $12.5 \%$ of the total population of the state. As of the latest report it is recognized as the third largest state in Kerala after Palakkad in the first and Idukki in the second and having an area of $3558 \mathrm{Km}^{2}$. It is being positioned at $76^{\circ} \mathrm{E}-78^{\circ} \mathrm{E}$ longitude and $11^{\circ} \mathrm{N}-10^{\circ} \mathrm{N}$ latitude in the geographical map. The district is bounded across its curvature by a coastal area (lowland) having over the Arabian Sea along the west, midland at the central position, and up to a hilly region (highland) which is the Western Ghats spanning along east. Malappuram is ranked fourth in its length of coastlines amongst the districts in Kerala, Malappuram has a coastline of $72 \mathrm{~km}$ which is almost $12 \%$ of the total coastline length of Kerala and is ranked fourth in the state for its coastline span. The district has an average temperature of $27.5^{\circ} \mathrm{C}$ and receives an average rainfall of 2,903 millimeters (114.29 inches) a year.

Data collected from the Kerala State Disaster Management which is also called in short as KSDMA, states that, many a number (for statistics 1,792no's) houses was damaged or deteriorated fully due to the natural effects or in a way due to the indirect impact resulted from flooding in between the month of August 2019, and the statistics of partly destructed houses is 14,552. The site selected to build upon the residential building is located in the eastern coastal area of Malappuram which is bounded by the river Chaliyar on one side.

The Flood resistant residential building will be designed according to the calculated loads using the characteristic materials based upon its characteristic strength and durability, thus it will resist flood. Multi-danger hazard evaluation won't be existing in Nepal. Likewise, it portrays streak floods that happened because of the overwhelming precipitation in hilltops and high mount areas, huge speed led to the trash flood in places of preceding height levels. Land area surveillance in the influenced zone was analyzed. Most of the evaluated structures and life savers were badly influenced during the April,15 Nepal tremors (Dipendra Gautam, You Dong (2017).

Kelman (2004) in his paper he spoke to a whole outline of the flood attributes alongside their pertinence for evaluating and examining the direct harm to the structures from swamping. This 
methodology is taken to characterize flood activities that attempt to cause impacts straightforwardly to the structure, in like manner causing harm or damages. In paper it centers the customary methodology of examining flood harm to structures which will center around harm from moderate ascent or moderate stature of the flood level. Attributes which identify with direct harm additionally incorporate powers, coercion, substance responses, and different effects.

In this paper, the swamp zone was dissected by utilizing the hydro zonal chart in which they can decide the proficiency and recurrence of flood as indicated by the time. The point by point solutions on examining of the qualities of dispersion by the structure utilization dependent on The flood parameters like flood profundity, flood span, the time of flooding and the utilization of flood detecting frameworks (Kelman,2002).

Haugen, Kaynia (2008) in their paper they have introduced a strategy for deciding the harm which is causing to the property affected by flotsam and jetsam in knowledge management and focuses on the standards of vital reactions of structures to flood agitation and furthermore delicacy bends in an $\mathrm{f} 18$ model for estimation of the building by harm state index. This strategy is as of now been tried on a flotsam and jetsam stream in European countries which showed mathematical odds somewhere in the range of 30 and 60 for arriving at the harming extent that turns to really happen on high numbers of structures on the zone (Schware, Robert, 1982).

\section{METHODOLOGY}

Figure 1 and Figure 2 depicts some of the actual images of flood affected sites in Malappuram during the recent floods of 2019 and shows the serious effects of landslides and the structural damages caused due to the buoyancy force of the water flow. Preparation of plan of Residential Building with AutoCAD then Analysis of Structural Elements using STAAD.Pro. After that Design of structural members and Modelling of residential building using REVIT Architecture 


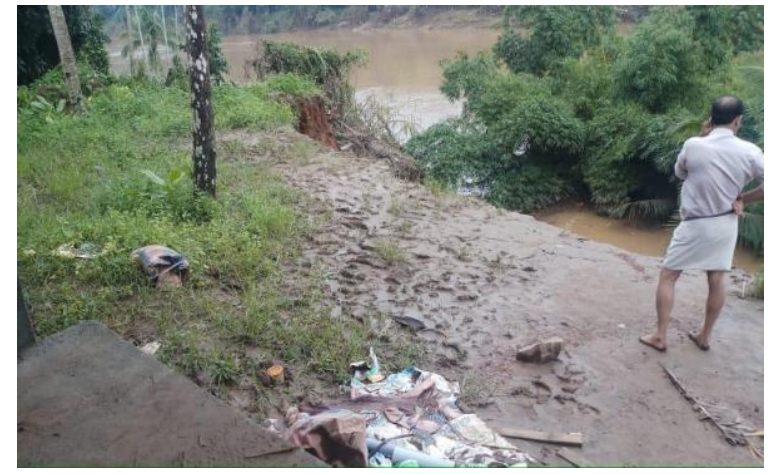

Figure 1 Depicts the effects of flood at proposed site, 2019

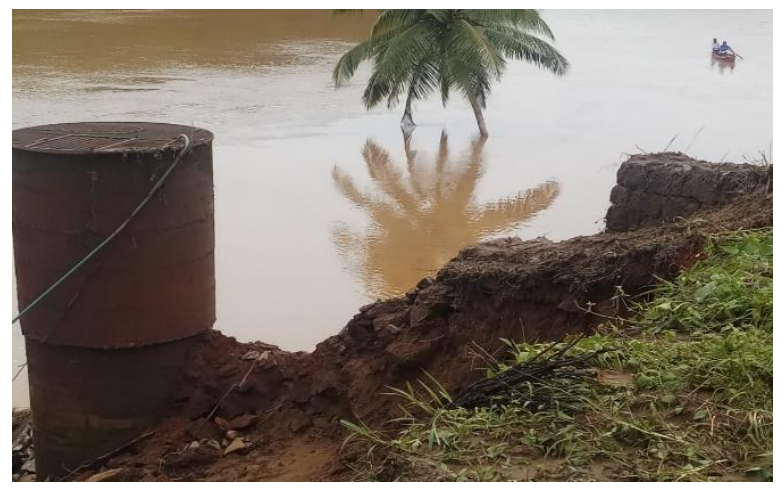

Figure 2 Depicts the open well damaged due to flood

\section{RESULTS AND DISCUSSIONS}

The plan of the building is done at AutoCAD 2016, which is in accordance with Indian standards keeping in mind all the necessary requirements. Structural Analysis is done using STAAD.pro, where Bending moment diagram, shear force diagram are obtained. Modelling is done using Revit Architecture.

\section{PLANNING \& SELECTION OF SITE}

The description of the structure and floor plan are discussed in detail below. The planning of the structural parts of the building has been studied earlier in 15CE302L computer aided structural analysis. The site is located in Malappuram, Kerala. The below shown Figure 3 depicts the selected location suitable for construction with the help of Google Earth software.

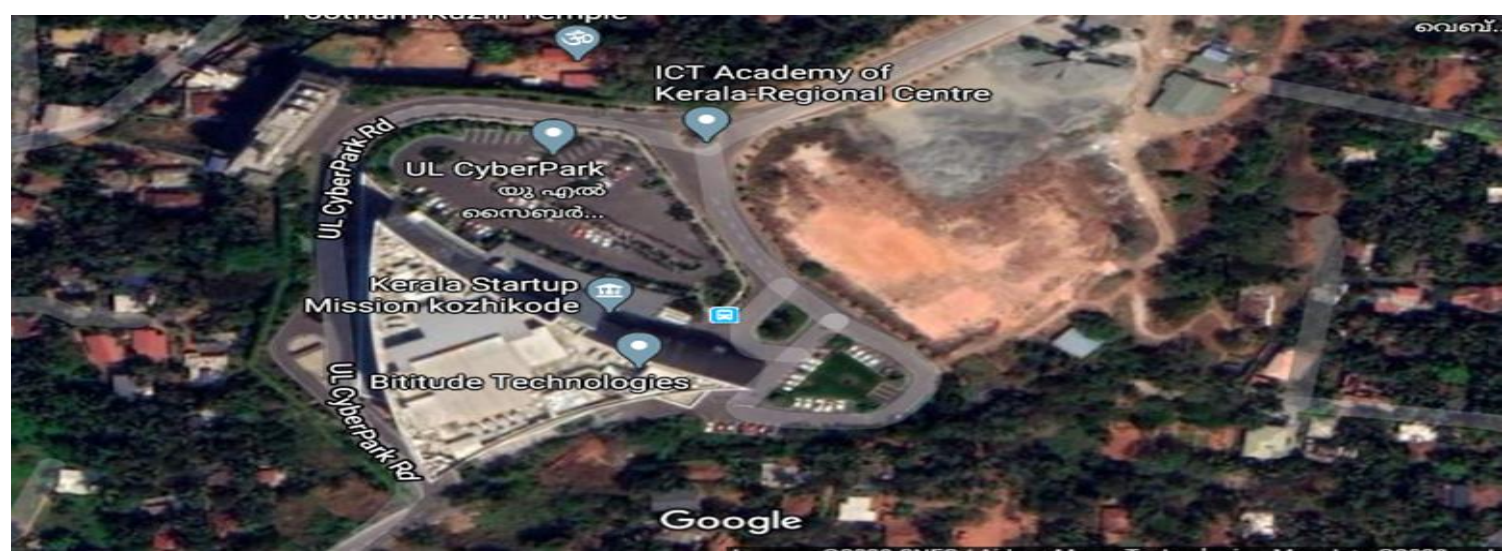

Figure 3 Google Maps image of the site 
Following the measurements using Map Developers software to analyse the area of the site, the requisite image is shown in Figure 3 and the derived area in Table 1.

Table 1 Site measurements

\begin{tabular}{|c|c|c|c|c|c|}
\hline Unit & feet $^{\mathbf{2}}$ & acres & miles $^{\mathbf{2}}$ & $\mathbf{k m}^{\mathbf{2}}$ & meter $^{\mathbf{2}}$ \\
\hline Area & 6835 & .16 & .001 & .001 & 635 \\
\hline
\end{tabular}

\section{PLAN OF BUILDING}

The proposed building plan for a Flood Resistant Residential Building $(\mathrm{G}+5)$ is shown in Figure 4 and Building description of the structure is shown in Table 2.

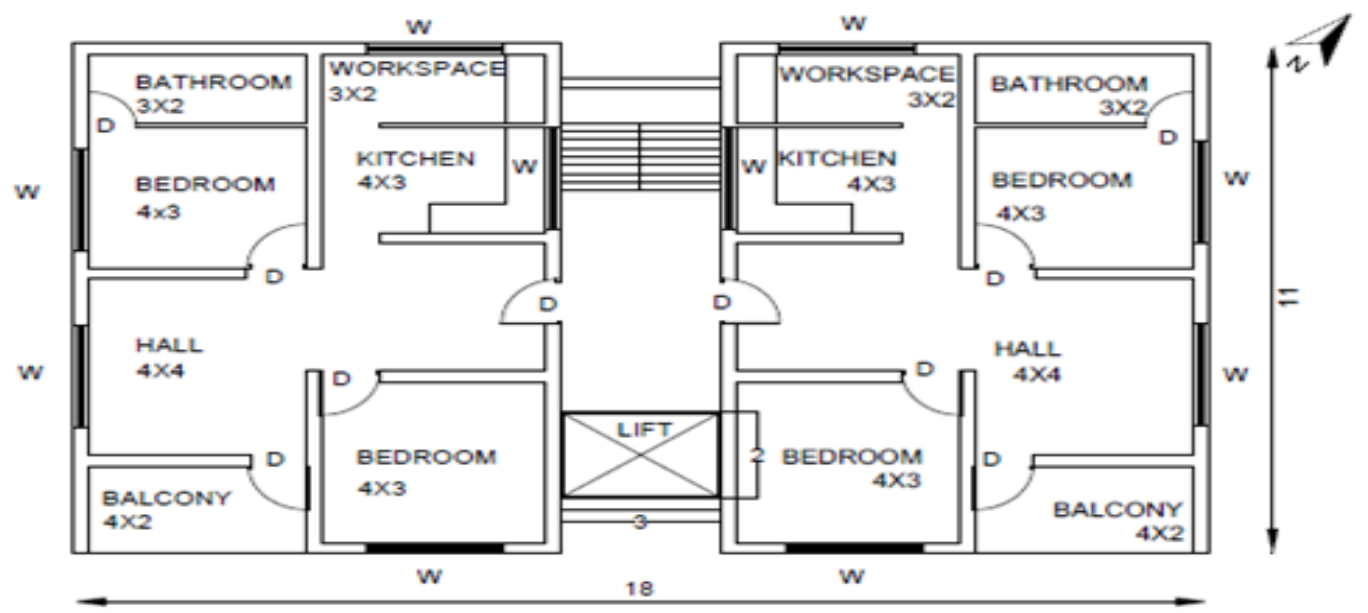

Figure 4 Depicts the structural diagram and position of the columns of the structure. 
Table 2 Building Description of the structure

\begin{tabular}{|l|c|}
\hline \multicolumn{1}{|c|}{ Type } & Area \\
\hline Total number of floors & $\mathrm{G}+5$ \\
\hline Total number of flats & 8 \\
\hline $\begin{array}{l}\text { Total number of flats in each } \\
\text { floor of the apartment }\end{array}$ & 2 \\
\hline $\begin{array}{l}\text { Total number of two bedroom } \\
\text { flats in the building }\end{array}$ & 8 \\
\hline $\begin{array}{l}\text { Total numbers of the three } \\
\text { bedroom flats in the building }\end{array}$ & 0 \\
\hline Type of apartment & Residential building \\
\hline Total land area of the building & $254 \mathrm{~m}^{2}$ \\
\hline $\begin{array}{l}\text { Built up area of the whole } \\
\text { residential complex site }\end{array}$ & $192.6 \mathrm{~m}^{2}$ \\
\hline Gross built up area of building & $85 \mathrm{~m}^{2}$ \\
\hline Carpet area per flat & $70 \mathrm{~m}^{2}$ \\
\hline
\end{tabular}




\section{MODELLING}

The following Figure 5 and depicts the structure modelling which was developed using Revit Architecture.

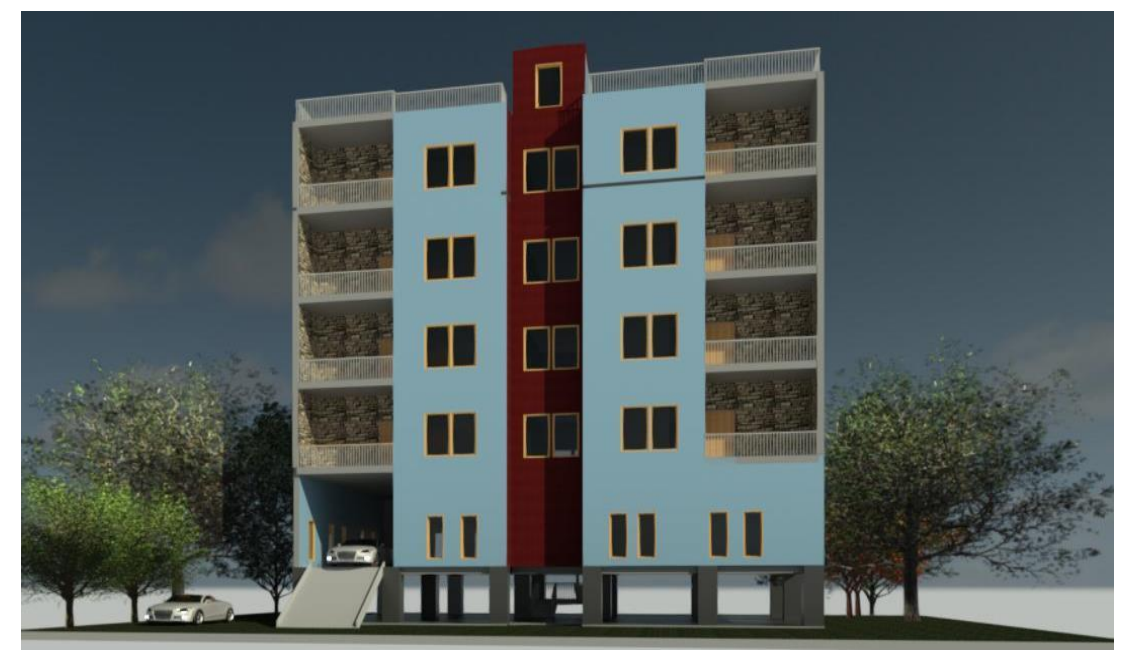

Figure 5 Elevation of the building

\section{ANALYSIS OF STRUCTURE}

\section{EVALUATION OF DESIGN LOAD}

Assessment of various loads on the structure is the important aspect in the design of the structures. The Indian Standards IS:875(1987) series recommended such loads for building and structures. So the possible loads for the building as per Indian Standards are,

- Dead load -Is of IS 875:1987 Part I

- Imposed or Live load - As per IS 875: 1987 Part II

\section{DEAD LOAD}

Dead load of a structure is the summation of the total self-weight of all materials and elements used whilst the construction of the structure. It is duly calculated in respect to the weight/mass of material alongside considering the dimensions of each structural element or member. Concrete, masonry and steel are the three crucial materials in which term construction is built upon. The following Table 3 about the unit weight detail of some material. 
Table 3 Unit weight of materials

\begin{tabular}{|c|l|c|}
\hline S.No. & \multicolumn{1}{|c|}{ Materials } & Unit Weight $\left(\mathbf{k N} / \mathbf{m}^{\mathbf{3}}\right)$ \\
\hline 1. & Reinforced Cement Concrete & 25 \\
\hline 2. & Plain Cement Concrete & 24 \\
\hline 3. & Masonry & 19.2 \\
\hline 4. & Steel & 7850 \\
\hline
\end{tabular}

(Source: Wikipedia)

\section{IMPOSED LOAD / LIVE LOAD}

It is the load which are calculated by an assumption that are to be produced due to the continuous or sustained use or occupancy of the building which includes the weight of movable partition which are termed distributed concentrated loads, due to impact vibration caused by these following occurrences and dust load exclusively wind, seismic, snow and other loads due to temporary change, creep, shrinkage and differential settlements etc. According to IS:875(1987) only UDL load is considered for analysis. The following Table 4 is about various loads for building.

Table 4 Imposed load on the Residential building

\begin{tabular}{|c|l|c|}
\hline S.No. & \multicolumn{1}{|c|}{$\begin{array}{c}\text { Type of } \\
\text { room }\end{array}$} & $\begin{array}{c}\text { Uniformly Distributed } \\
\text { Loads }\end{array}$ \\
\hline 1. & Bedroom & 2.0 \\
\hline 2. & Kitchen & 2.0 \\
\hline 3. & Toilet & 2.0 \\
\hline 4. & Balcony & 3.0 \\
\hline 5. & Passage & 3.0 \\
\hline 6. & Dinning & 2.0 \\
\hline
\end{tabular}

\section{ANALYSIS OF BUILDING}

The following Figure 6 depicts the 3D diagram of the structure obtained as result from STAAD.Pro. Table 5 indicates the moment distribution and Table 6 indicates the force distribution. 


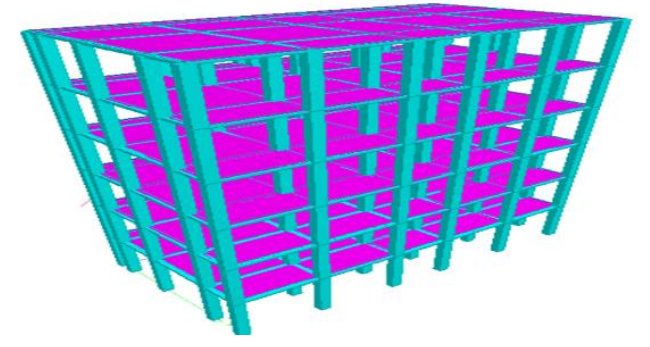

Figure 6 3D diagram of the structure

Table 5 Moment distribution table

\begin{tabular}{|l|l|r|r|r|r|r|r|}
\hline Rect & Max+v & 1180.30 & & & & & \\
$0.50 x 0.40$ & $\mathrm{e}$ & 7.262 & 5.927 & 0.268 & 12.849 & 8.671 \\
\hline & Max-ve & -3.572 & -4.262 & -7.634 & -0.268 & 17.747 & -8.671 \\
\hline $\begin{array}{l}\text { Rect } \\
0.17 x 0.25\end{array}$ & $\begin{array}{l}\text { Max+v } \\
\text { e }\end{array}$ & 2.589 & 17.539 & 0.304 & 0.191 & 0.636 & 14.637 \\
\hline & Max-ve & -1.417 & 17.539 & -0.304 & -0.191 & -0.595 & -8.549 \\
\hline $\begin{array}{l}\text { Rect } \\
0.17 x 0.25\end{array}$ & $\begin{array}{l}\text { Max+v } \\
\text { e }\end{array}$ & 3.498 & 17.991 & 0.789 & 0.084 & 0.455 & 20.28 \\
\hline & Max-ve & -9.452 & 40.998 & -0.789 & -0.084 & -0.455 & 20.231 \\
\hline
\end{tabular}

Table 6 Force distribution table

\begin{tabular}{|l|r|r|r|r|r|r|r|}
\hline 1 DL & 0 & -0.585 & -0.654 & 0.562 & 0.631 & 0.631 & -0.654 \\
\hline & 1 & 0.419 & 0.383 & -0.441 & -0.406 & 0.419 & -0.441 \\
\hline & 2 & 0.565 & 0.564 & -0.588 & -0.586 & 0.565 & -0.588 \\
\hline & 3 & -0.145 & -0.113 & 0.123 & 0.09 & 0.123 & -0.145 \\
\hline & 4 & -1.713 & -1.646 & 1.69 & 1.624 & 1.69 & -1.713 \\
\hline 2 LL & 0 & -2.544 & -2.578 & 2.548 & 2.582 & 2.582 & -2.578 \\
\hline & 1 & 0.341 & 0.324 & -0.337 & -0.32 & 0.341 & -0.337 \\
\hline & 2 & 1.325 & 1.325 & -1.321 & -1.321 & 1.325 & -1.321 \\
\hline & 3 & 0.326 & 0.342 & -0.322 & -0.338 & 0.342 & -0.338 \\
\hline & 4 & -2.574 & -2.541 & 2.579 & 2.545 & 2.579 & -2.574 \\
\hline 3 FL & 0 & -0.848 & -0.859 & 0.849 & 0.861 & 0.861 & -0.859 \\
\hline & 1 & 0.114 & 0.108 & -0.112 & -0.107 & 0.114 & -0.112 \\
\hline & 2 & 0.442 & 0.442 & -0.44 & -0.44 & 0.442 & -0.44 \\
\hline & 3 & 0.109 & 0.114 & -0.107 & -0.113 & 0.114 & -0.113 \\
\hline & 4 & -0.858 & -0.847 & 0.86 & 0.848 & 0.86 & -0.858 \\
\hline
\end{tabular}

The analysis of the beam and the column have been completed using STAAD.Pro software.The beam is having breadth and width of $500 \mathrm{~mm}$ and $400 \mathrm{~mm}$ respectively.The beam are designed 
for a 5 storeys and live load reduction factor 1. The factored moment and factored forces calculated using fy $=415 \mathrm{MPa}$ and $\mathrm{fck}=30 \mathrm{MPa}$ is $473 \mathrm{kN}-\mathrm{m}$ and $343 \mathrm{kN}$. The column is of length $3000 \mathrm{~mm}$, breadth $400 \mathrm{~mm}$ and width $500 \mathrm{~mm}$. The calculated design force and design moment using fy $=415 \mathrm{MPa}$ and $\mathrm{fck}=30 \mathrm{MPa}$ is $118.307 \mathrm{kN}$ and $128.49 \mathrm{kNm}$ respectively. The height of each storey id $3600 \mathrm{~mm}$ and the elevation of storey 1 is $3600 \mathrm{~mm}$ and storey 2 $7200 \mathrm{~mm}$ and subsequently and increase of $3600 \mathrm{~mm}$ for each and finally storey $524600 \mathrm{~mm}$ serving as the master storey.

\section{CONCLUSION}

The project was done to plan, model, analyze and design flood resistant residential buildings $(\mathrm{G}+5)$ in Malappuram, Kerala. The design specifications were strictly followed in the course of the project and designing the structure. The proper and recommended softwares was used and the analysis of the structure was obtained. The material reinforcements and design parameters were executed according to the analysis report obtained by the STAAD.Pro and used accordingly in the design.

The project is found to be highly sustainable on grounds of flood resisting area and highly durable and economically feasible for both the organization and the client. Due to the presence of high length retaining walls much of the water logging in the area is being reduced and much of the soil erosion or conditions for any landslides to occur as in the previous scenario are reduced hugely.

The project was done taking into consideration that the site is in flood zone 3 and the water level acted in the previous floods of 2019. Environmental constraint is highly taken for consideration and design changes and suitability are made in order to minimize the future causes or occurrences of water logging due to flood.

Manufacturability and the design are done after software analysis in STAAD.Pro and the chances of structural failure due to the impact of high loads or water logging is certainly reduced to the peak. All the design steps are done as per IS 456:2000 and also by welcoming future practices and uses in American Standard Codes. Beams are designed for flexure and shear as per SP16:1980. All major criteria for selecting the reinforcement is followed as stipulated by IS 456:2000. Foundation is designed on the basis of soil type and loading as IS 456:2000. 


\section{REFERENCES}

IS: 456: 2000 Plain and Reinforced Concrete -Code of Practice, 4th Revision, BIS, New-Delhi. IS: 875 (Part 1): 1987, Code of practice for design loads (other than earthquake) for buildings and structures: Part-1 Dead loads - unit weights of building materials and stored materials, 2th Revision, BIS, New Delhi.

IS: 875 (Part 2): 1987, Code of practice for design loads (other than earthquake) for buildings and structures: Part-2 Imposed Loads, 2th Revision, BIS, New Delhi J.Birkmann. Measuring vulnerability to promote disaster-resilient societies: conceptual frameworks and definitions, United Nation Press, New York, USA, 2006, Page. 7-54.

Dipendra Gautam, You Dong (2017). Is flow velocity big parameter overflowing damage modelling?, Natural Hazards Earth System Sciences, Page 1-15.

Kelman,(2002). I. Physical Flood Vulnerability of Residential Properties in Coastal, Eastern England, Ph.D. Dissertation, University of Cambridge, U.K coast,,Page 2-12.

AndrásPark (2019). paper he has analyzed and referred studies about various disasters are increasing over the past twenty years between 1996 and 2015, Canada.

Win.S (2018). Flood Resisting Structure in his paper talks about disaster risk management and the way it's visiting affect the buildings and also the structures. 2th Revision, AIISSCE.

Haugen E.D. and Kaynia(2008) A.M. Vulnerability of structures impacted by debris flow, Landslides and Engineered Slopes, Taylor \& Francis Group, London, ISBN, 2008, Page 5-19.

Kewbich. (2009). Highway engineering paper one thing has investigated the importance of flow velocity, water depth, and combinations of these two parameters on various types of damages to buildings and roads, USA.

Schware, Robert, 1982. "Official and Folk Flood Warning Systems: An Assessment", Environmental Management, Vol. 6, No. 3, pp. 209-216.

Hughes, Richard, 1982. "Effects of Flooding upon Buildings in Developing Countries", Disasters, Vol. 6, No. 3, pp. 183-194, 1982.

Owen, J.H,(1980) Materials for Flood and Their Warning Systems, U.S. Dept. of Commerce.

Changnon S, Kundel K .1999. Record flood-producing rainstorms of 17-18 July 1996 in the Chicago Metropolitan area. 
Chen XQ, Xie H .1999. Study on regionalization of debris flow danger degree under GIS support. Journal of Soil Erosion and Soil and Water Conservation 5 (6): 46-50.I

Delrieu G, Ducrocq V, Gaume. 2005. The Catastrophic Flash-Flood Event of 8-9 September 2002 in the Gard Region. Journal of Hydrometeor 6: 34-52. 